\title{
LA TEORÍA “EX ANTE” DE LA TASA DE INTERÉS
}

John Maynard Keynes*

$\mathrm{D}$ espués de leer los artículos de los profesores Pigou y Ohlin, y los de los señores Robertson y Hawtrey, publicados en el último número de The Economic Journal, creo que el señor Robertson resumió muy bien la situación diciendo que titubeo ante una "difícil Tía Sally de edad incierta”. ¡Mientras que la verdad es una, el error es de muchos y prometo renunciar a cualquier intento de sostener lo contrario!

En lo que sigue me limito a la discusión entre el profesor Ohlin y yo porque pienso que es la más fructífera. Él me obligó a considerar un importante eslabón de la cadena causal que descuidé antes y contribuyó a hacer una gran mejora en mi análisis; y en cuanto a la diferencia que aún subsiste entre nosotros, no abandono la esperanza de convencerlo. Aunque para ello tal vez deba aguardar a un futuro artículo que pienso escribir sobre la relación entre el análisis ex ante y expost en su totalidad y el esquema analítico de mi Teoría general. Entre tanto, comento su última contribución.

Para el profesor Ohlin, la tasa de interés depende de la interacción en el margen entre la oferta de crédito nuevo debida al ahorro ex ante y la demanda de crédito nuevo proveniente de la inversión ex ante. Creo entender que la cantidad de ahorro ex ante en cual-

* Tomado de The Economic Journal 47, 188, 1937, pp. 663-669. Traducción de Alberto Supelano. Fecha de recepción: 27-10-2016, fecha de aceptación: 27-04-2017. Sugerencia de citación: Keynes, J. M., "La teoría 'ex ante' de la tasa de interés", Revista de Economía Institucional 19, 36, 2017, pp. 347-353. DOI: https://doi.org/10.18601/01245996.v19n36.15.

${ }^{1}$ Pigou, A. C. "Real and money wage rates in relation to unemployment", 47, 187, 1937, pp. 405-422; Ohlin, D.; H. Robertson y R. G. Hawtrey. "Alternative theories of the rate of interest: Three rejoinders", 47, 187, pp. 423-443. Con respecto al artículo del profesor Pigou, ver mi nota "Prof. Pigou on money wages in relation to unemployment", Economic Journal 47, 188, 1937, pp. 743-745. 
quier periodo depende de las decisiones subjetivas que se toman en ese periodo para hacer ahorros objetivos del ingreso que se recibirá después y, en forma análoga, que el monto de la inversión ex ante depende de las decisiones subjetivas de invertir que después tendrán un efecto objetivo. Ahora bien, la inversión ex ante es un fenómeno importante y genuino porque las decisiones se deben tomar y el crédito o "financiación" se debe conseguir antes del proceso real de inversión ${ }^{2}$; aunque el monto del crédito preliminar demandado no sea necesariamente igual al monto de la inversión proyectada ${ }^{3}$. Sin embargo, no es necesario que los individuos decidan qué parte de su ingreso futuro van a ahorrar en el mismo momento en que los empresarios deciden invertir. Para empezar, no saben cuáles serán sus ingresos, en especial si provienen de beneficios. Pero, en primer lugar, aunque tengan una opinión preliminar a ese respecto no tienen necesidad de tomar una decisión definitiva (como sí tienen que tomarla los inversionistas); en segundo lugar, no la toman al mismo tiempo y, en tercer lugar, como regla general, no agotan su efectivo antes de recibir el ingreso que se proponen ahorrar, la única manera como podrían proporcionar a los inversionistas la "financiación" en la fecha en que la requieren. Por último, aun si estuvieran dispuestos a endeudarse contra sus ahorros futuros, no se podría disponer de efectivo adicional de esa manera, a menos que cambiara la política bancaria. Con seguridad, nada es más cierto que el ahorro ex ante no es la principal fuente de suministro del crédito o "financiación" requerida para la inversión ex ante. En un momento analizaremos el papel que desempeña, si desempeña alguno.

¿Cómo se suministra? Cuando el empresario decide invertir debe haber previsto dos detalles: primero, que pueda obtener suficiente financiación de corto plazo durante el periodo de producción de la inversión; segundo, que pueda cubrir sus deudas emitiendo títulos de largo plazo en condiciones satisfactorias. A veces puede usar recursos propios y emitir a la vez títulos de largo plazo, pero esto no afecta el monto de la "financiación" que debe conseguir en el mercado como un todo; solo tiene que ver con el canal a través del cual llega al empresario y con la posibilidad de conseguir parte de ella recurriendo a efectivo propio o del público. Por tanto, es conveniente considerar ese doble proceso como el caso típico.

\footnotetext{
${ }^{2}$ En lo que sigue, uso el término "financiación” para designar el crédito requerido durante el lapso que transcurre entre la planeación y la ejecución.

3 Por ejemplo, cuando se emprende la construcción de un ferrocarril, no es usual que antes de cavar la primera zanja se solicite un préstamo por el total de lo que costará.
} 
Ahora bien, los mercados de préstamos nuevos de corto plazo y de títulos nuevos de largo plazo son en esencia los mismos que los de préstamos y títulos viejos; para lo que estamos discutiendo aquí no son relevantes las anomalías menores, como las que puede ocasionar la imperfección del mercado entre banqueros y otros proveedores de financiación o entre diferentes segmentos del mercado de inversión. Por tanto, los términos de la oferta de la financiación requerida para la inversión ex ante dependen del estado existente de las preferencias de liquidez (junto a las previsiones de los empresarios sobre las condiciones para obtener esa financiación cuando llegue el momento) y de la forma en que la política del sistema bancario administra la oferta de dinero. Por tanto, en líneas generales, la tasa de interés relevante para la inversión ex ante es la tasa de interés determinada por la cantidad de dinero y el estado de las preferencias de liquidez existentes en la fecha en que se debe disponer de la financiación requerida por las decisiones de inversión. Hasta aquí, no hay que hacer ninguna modificación a mi análisis anterior.

$\mathrm{E} 1$ factor adicional que descuidé anteriormente, y sobre el que el profesor Ohlin dirigió la atención al subrayar el carácter ex ante de la inversión, es el siguiente. Durante el interregno entre el momento en que el empresario contrata su financiación y el momento en que efectúa la inversión -y solo durante ese periodo- hay una demanda adicional de liquidez, sin que necesariamente surja aún una oferta adicional. Para que el empresario sienta que tiene liquidez suficiente para embarcarse en su transacción, algún otro debe aceptar una disminución de su liquidez, al menos por un tiempo. El profesor Ohlin parece sugerir que esta oferta de financiación líquida proviene de aquellos individuos que tienen la intención de ahorrar en una fecha futura. Pero, si es así, ¿cómo lo hacen? Deben agotar sus saldos de efectivo, acudir a sobregiros o aceptar títulos pagaderos a plazos durante el periodo total de la inversión. Admito que la intención de ahorrar a veces afecta la disposición a perder liquidez por algún tiempo. Es cierto que se debería incluir este motivo en la lista de factores que afectan el estado de las preferencias de liquidez (pues no se subraya suficientemente haciendo mera referencia a la cantidad de ingresos futuros esperados). Pero es solo uno entre muchos otros y, en la práctica (tal vez pensé), uno de los menos importantes. Incluso en lo que a primera vista parecería un caso plausible de ahorro ex ante: cuando una persona ordena construir una casa para sí misma a una empresa a la que hipoteca sus ahorros futuros para garantizarle el pago, no es su promesa la que proporciona al constructor la financiación reque- 
rida, sino los recursos que la sociedad constructora obtiene (sin duda, respaldada por las promesas de pago de sus miembros), ofreciendo una tasa de interés adecuada, del conjunto de recursos líquidos de la economía, bien sea que provengan del efectivo que pueda aportar el propietario o de nuevo efectivo suministrado por los bancos. El ahorrador ex ante no tiene efectivo, pero lo que requiere el inversionista ex ante es efectivo. Por el contrario, la financiación requerida durante el interregno entre la intención de invertir y su realización efectiva es suministrada principalmente por especialistas, en particular por los bancos, que organizan y manejan el fondo rotatorio de financiación líquida.

Pues la "financiación" es en esencia un fondo rotatorio. No emplea ahorros. Para la comunidad en su conjunto es solo un asiento contable. Tan pronto se "usa", es decir, cuando se gasta, la falta de liquidez se cubre automáticamente y la disposición a perder liquidez temporalmente queda disponible para ser de nuevo utilizada. En el agregado, al final del periodo en consideración, la financiación que cubre el interregno necesariamente "se liquida", para emplear la expresión que los banqueros usan en un contexto más limitado.

En un esquema simplificado, concebido para resaltar la esencia de lo que sucede pero que es de hecho bastante representativo de la vida real, se puede suponer que la "financiación" es suministrada en su totalidad por los bancos durante el interregno; y esto explica por qué su política es tan importante en la determinación del ritmo al que pueden avanzar las nuevas inversiones. El Dr. Herbert Bab me sugirió que se puede considerar que la tasa de interés es determinada por la relación entre los términos a los que el público desea tener mayor o menor liquidez y los términos a los que los bancos están dispuestos a tener mayor o menor iliquidez. Creo que esta es una manera esclarecedora de expresar la teoría de la tasa de interés basada en la liquidez, particularmente en el campo de la "financiación".

Vuelvo al tema de la financiación como fondo rotatorio. En general, el flujo de la financiación nueva necesaria para la inversión corriente ex ante es suministrado por la financiación liberada por la inversión corriente ex post. Cuando el flujo de inversión mantiene una tasa constante, de modo que el flujo de inversión ex ante es igual al flujo de inversión ex post, la financiación puede reciclarse en su totalidad sin cambios en la posición de liquidez. Pero cuando la tasa de inversión cambia, en el sentido de que la tasa de inversión ex ante no es igual a la tasa de inversión ex post, la cuestión se debe examinar más a fondo. 
Aunque el ahorro ex ante tendiera a cambiar en la misma dirección y al mismo tiempo que la inversión ex ante, esto -como ya señalé- solo resolvería la dificultad si los ahorradores ex ante estuvieran dispuestos a reducir el efectivo existente en una cuantía igual a su ahorro prospectivo; $\mathrm{y}$ aunque el ahorro ex ante puede tener alguna influencia favorable en las preferencias de liquidez corrientes, es dudoso que tenga una influencia decisiva. En todo caso, el ahorro ex ante solo puede actuar mediante su influencia en las preferencias de liquidez actuales.

De todo esto se deduce una conclusión importante que puede atenuar las diferencias entre mi posición y la del profesor Ohlin, y quizá también con la de quienes sostienen que los cambios en el monto de préstamos bancarios tienen una influencia decisiva en la tasa de interés.

Esa conclusión es que si no cambian las preferencias de liquidez del público (distinto de los inversionistas empresariales) y de los bancos, cualquier exceso de la financiación requerida para la producción corriente ex ante (no escribo "inversión" porque igual sucede en toda producción que se deba planear de antemano), con respecto a la financiación liberada por la producción corriente ex post, inducirá un aumento de la tasa de interés; si fuese menor induciría una reducción. No debería haber descuidado este punto porque es la piedra angular de la teoría de la tasa de interés basada en la liquidez. Es cierto que tuve en cuenta el efecto de un incremento de la actividad efectiva sobre la demanda de dinero. Pero no consideré el efecto de un incremento de la actividad planeada, que se superpone al primero y, algunas veces, puede ser el más importante de los dos porque el efectivo que requiere puede rotar mucho más lentamente. Así como un incremento de la actividad real debe elevar la tasa de interés (como siempre he explicado), salvo que los bancos o el resto del público estén más dispuestos a liberar efectivo, un incremento de la actividad planeada -como añado ahora- debe tener una influencia similar, superpuesta ${ }^{4}$.

Pero esto solo sirve para reforzar la teoría del interés basada en la liquidez contra la teoría basada en los ahorros, bien sean ex post o ex ante. E1 hecho de que los ahorros ex post aumenten en la misma cantidad que las inversiones ex post no cambia la situación en lo más mínimo. Un mayor nivel de actividad planeada incrementa, mientras perdure, la demanda de liquidez, independientemente del nivel de ahorro. Eso mismo es cierto bien sea que la actividad planeada por el empresario o el gasto planeado por el público se dirijan a inversión o

\footnotetext{
${ }^{4}$ Esto no apoya la teoría de la tasa de interés basada en los préstamos, que sigue siendo una teoría a medias porque tiene en cuenta los cambios en la oferta de dinero pero no los cambios en las preferencias de liquidez del público prestamista.
} 
a consumo. ¿Cómo trataría el profesor Ohlin este punto? ¿Diría que la financiación requerida por el incremento en la actividad planeada para producir bienes de consumo es suministrada por el consumo $e x$ ante? Eso debería decir, porque el consumo es tan eficaz para liquidar la financiación de corto plazo como el ahorro. No hay diferencias entre ellos. Si el empresario percibiera las intenciones de consumo ex ante en la mente de los consumidores, no solo tendría la misma seguridad de obtener liquidez y pagar oportunamente a su banco que cuando intuye un ahorro ex ante, sino una seguridad aún mayor, porque no existe el riesgo de que el consumo, cuando se realice, tome la forma de un mayor deseo de efectivo. La única ventaja del ahorro ex ante sobre el consumo ex ante reside en su posible efecto sobre la preferencia de liquidez actual de los individuos.

La demanda de liquidez se puede dividir entre lo que podemos llamar demanda activa, que depende del nivel de actividad real y planeado, y la demanda inactiva, que depende del estado de confianza de los poseedores pasivos de títulos y activos; mientras que la oferta depende de los términos en que los bancos están dispuestos a tener mayor o menor liquidez. En un estado de expectativas dado, ambas demandas dependen de la tasa de interés. $Y$ a veces de la oferta, pero no necesariamente, pues la política bancaria se puede orientar a regular la cantidad de dinero sin prestar mucha atención a la tasa de interés. En todo caso, dadas las expectativas del público y la política de los bancos, la tasa de interés es la tasa a la cual se equilibran la oferta y la demanda de recursos líquidos. E1 ahorro no interviene en absoluto. La actividad que se completa, bien sea que sus ingresos se destinen a inversión o a consumo, se liquida a sí misma y no añade demandas netas adicionales a la oferta de recursos líquidos (excepto, en forma indirecta y a largo plazo, en la medida en que la demanda inactiva de liquidez depende en parte de la riqueza agregada).

Sin embargo, el punto sigue siendo que la transición de un nivel bajo de actividad a otro más alto implica una mayor demanda de recursos líquidos que no se puede satisfacer sin elevar la tasa de interés, a menos que los bancos estén dispuestos a prestar más efectivo o el resto del público a liberar más efectivo a la tasa vigente. Si no hay cambios en la posición de liquidez, el público puede ahorrar ex ante y ex post y ex cualquier otra cosa hasta quedar exangüe, sin aliviar el problema en lo más mínimo, excepto cuando el resultado de sus esfuerzos sea volver al nivel de actividad anterior.

Esto significa que, en general, los bancos tienen una función clave en la transición de un nivel de actividad bajo a uno alto. Si se nie- 
gan a conceder más crédito, la creciente congestión del mercado de préstamos de corto plazo o del mercado de acciones nuevas, sea cual sea el caso, inhibirá el crecimiento, sin que importe la cantidad de ingresos futuros que el público se proponga ahorrar. Por otra parte, siempre habrá la cantidad exacta de ahorro ex post para respaldar la inversión ex post $\mathrm{y}$, así, liberar la financiación que se utilizó previamente. El mercado de inversión se puede llegar a congestionar por una escasez de efectivo, nunca por una escasez de ahorro. Esta es la más fundamental de mis conclusiones en este campo.

Vale la pena mencionar un ejemplo obiter dictum de mi planteamiento anterior, que puede ilustrar la esencia del argumento. En Gran Bretaña, los bancos ponen gran atención en la cantidad de préstamos pendientes y de depósitos, pero no en el volumen de sobregiros autorizados y no utilizados por sus clientes. No se sabe cuál es la cantidad agregada de estos últimos -quizá ni los mismos bancos lo sepan- ni tampoco cuál es la proporción entre los recursos que se mantienen por motivos de pura precaución, que posiblemente no se utilicen en el futuro cercano, y los que están asociados a la actividad planeada inminente. No obstante, este es un sistema ideal para mitigar los efectos de una demanda creciente de financiación ex ante sobre el sistema bancario. Pues significa que no existen presiones efectivas sobre los recursos del sistema bancario hasta que la financiación se utiliza realmente, es decir, hasta la fase en que la actividad planeada pasa a convertirse en actividad real. Así, en la medida en que se emplean los sobregiros del sistema y el sistema bancario ignora los sobregiros no utilizados, la presión resultante de la actividad planeada no se superpone a la presión resultante de la actividad efectiva. En este caso, la transición de un nivel de actividad bajo a uno alto se puede lograr con una menor presión sobre la demanda de liquidez y sobre la tasa de interés. 